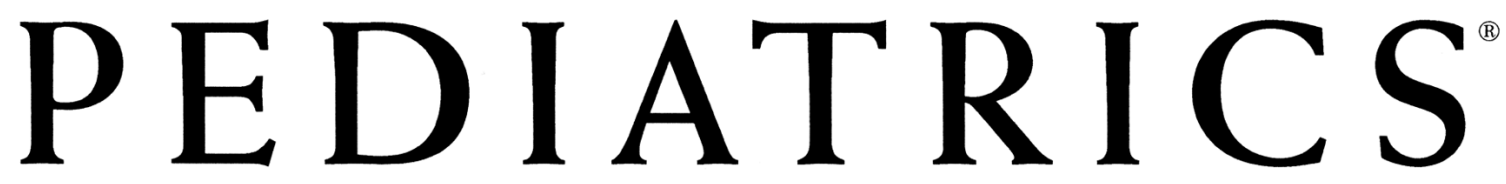

OFFICIAL JOURNAL OF THE AMERICAN ACADEMY OF PEDIATRICS

\title{
Accuracy of MUAC in the Detection of Severe Wasting With the New WHO Growth Standards
}

Miguel Ángel Luque Fernández, Pascale Delchevalerie and Michel van Herp Pediatrics 2010;126; e195; originally published online June 29, 2010;

DOI: $10.1542 /$ peds.2009-2175

The online version of this article, along with updated information and services, is located on the World Wide Web at: http://pediatrics.aappublications.org/content/126/1/e195.full.html

PEDIATRICS is the official journal of the American Academy of Pediatrics. A monthly publication, it has been published continuously since 1948. PEDIATRICS is owned, published, and trademarked by the American Academy of Pediatrics, 141 Northwest Point Boulevard, Elk Grove Village, Illinois, 60007. Copyright () 2010 by the American Academy of Pediatrics. All rights reserved. Print ISSN: 0031-4005. Online ISSN: 1098-4275.

\section{American Academy of Pediatrics}




\section{Accuracy of MUAC in the Detection of Severe Wasting With the New WHO Growth Standards}

AUTHORS: Miguel Ángel Luque Fernández, MA, MPH, FETP, Pascale Delchevalerie, MSc, and Michel Van Herp, MD, $\mathrm{MPH}$

Medical Department, Brussels Operational Center, Doctors Without Borders, Brussels, Belgium

\section{KEY WORDS}

malnutrition, anthropometry, mid-upper-arm circumference, diagnostic errors, epidemiology

\section{ABBREVIATIONS}

MUAC-mid-upper-arm circumference

NCHS - National Center for Health Statistics

WHO-World Health Organization

$\mathrm{Cl}$-confidence interval

Dr Luque Fernández's current affiliation is the Brussels-Capital Health and Social Observatory, Research Centre for the Joint College Services of the Joint Community Commission, Brussels, Belgium.

www.pediatrics.org/cgi/doi/10.1542/peds.2009-2175

doi:10.1542/peds.2009-2175

Accepted for publication Mar 17, 2010

Address correspondence to Miguel Ángel Luque Fernández, MA, MPH, FETP, Médecins Sans Frontières OCB-Belgique, Medical Department, Rue Dupré 97, 1090 Jette, Brussels, Belgium. E-mail: miguel.angel.luque@brussels.msf.org or watzilei@hotmail.com

PEDIATRICS (ISSN Numbers: Print, 0031-4005; Online, 1098-4275).

Copyright (C) 2010 by the American Academy of Pediatrics

FINANCIAL DISCLOSURE: The authors have indicated they have no financial relationships relevant to this article to disclose.
WHAT'S KNOWN ON THIS SUBJECT: MUAC measurements are used to screen rapidly for malnutrition among children 6 to 59 months of age. With the introduction of a new growth curve for children by the WHO in 2006, an evaluation of MUAC diagnostic accuracy is needed.

WHAT THIS STUDY ADDS: This study confirms the need to change the MUAC cutoff value from $<110 \mathrm{~mm}$ to $<115 \mathrm{~mm}$. This change is needed to maintain the same diagnostic accuracy and to identify children at greatest risk of death resulting from severe wasting.

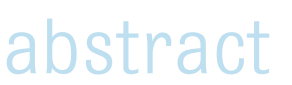

OBJECTIVES: The objectives of this study were to estimate the accuracy of using mid-upper-arm circumference (MUAC) measurements to diagnose severe wasting by comparing the new standards from the World Health Organization (WHO) with those from the US National Center for Health Statistics (NCHS) and to analyze the age independence of the MUAC cutoff values for both curves.

METHODS: We used cross-sectional anthropometric data for 34937 children between the ages of 6 and 59 months, from 39 nutritional surveys conducted by Doctors Without Borders. Receiver operating characteristic curves were used to examine the accuracy of MUAC diagnoses. MUAC age independence was analyzed with logistic regression models.

RESULTS: With the new WHO curve, the performance of MUAC measurements, in terms of sensitivity and specificity, deteriorated. With different cutoff values, however, the WHO standards significantly improved the predictive value of MUAC measurements over the NCHS standards. The sensitivity and specificity of MUAC measurements were the most age independent when the WHO curve, rather than the NCHS curve, was used.

CONCLUSIONS: This study confirms the need to change the MUAC cutoff value from $<110 \mathrm{~mm}$ to $<115 \mathrm{~mm}$. This increase of $5 \mathrm{~mm}$ produces a large change in sensitivity (from $16 \%$ to $25 \%$ ) with little loss in specificity, improves the probability of diagnosing severe wasting, and reduces false-negative results by $12 \%$. This change is needed to maintain the same diagnostic accuracy as the old curve and to identify the children at greatest risk of death resulting from severe wasting. Pediatrics 2010;126:e195-e201 
Human arms contain subcutaneous fat and muscle mass. Under conditions of reduced food intake, lower levels of subcutaneous fat and muscle mass tend to correspond to a decrease in the mid-upper-arm circumference (MUAC). This measurement can be used to diagnose malnutrition. ${ }^{1-3}$ MUAC is easy to measure and is relatively independent of gender and age. ${ }^{4}$ Because of the simplicity and low cost of measuring MUAC, it is used to screen rapidly for malnutrition among children 6 to 59 months of age .5,6 MUAC cutoff points of $125 \mathrm{~mm}$ (indicating global malnutrition) and $110 \mathrm{~mm}$ (indicating severe wasting) have been proposed for all children $<5$ years of age. ${ }^{?}$

Weight for height, expressed as a $z$ score, is used to define severe wasting. A weight-for-height level less than a $z$ score cutoff value of -3 is internationally recognized as severe wasting. In 2006, a new curve growth standard for assessing the growth of children throughout the world was introduced by the World Health Organization (WHO). A study comparing curves offered by the WHO and the US National Center for Health Statistics (NCHS) for diagnosis of severe wasting concluded that the WHO curve would identify more children with a high risk of death and would increase the number of children classified as experiencing severe wasting. ${ }^{8}$ Therefore, it is also important to compare the accuracy of the current MUAC cutoff point for severe wasting $(110 \mathrm{~mm})$ against the standard measures, that is, the 1977 child growth standards of the US NCHS ${ }^{9}$ and the 2006 WHO reference curve..$^{10}$ The objectives of this study were to estimate the accuracy of using MUAC measurements to diagnose severe wasting, defined as a weight-for-height $z$ score less than -3 without bipedal edema, by comparing the new WHO curve with the NCHS curve and to ana- lyze the age independence of the MUAC cutoff values of both curves.

\section{METHODS}

Data were obtained from 39 nutritional surveys conducted by Doctors Without Border in 10 countries, that is, Angola, Burundi, Malawi, Sierra Leona, Ethiopia, Niger, Burkina Faso, Chad (Darfur), India, and Afghanistan. Gender, weight, height, and MUAC were recorded for all children. The weight-forlength ratio was calculated for children who were $<24$ months of age. A total of 34937 children between 65 and $110 \mathrm{~cm}$ in height without bipedal edema were included in our analyses. The device used to measure the MUAC of children was a plastic, colored, insertion tape (incapable of stretching and unresponsive to temperatures) marked in millimeters, with cutoff points from red to yellow at $110 \mathrm{~mm}$ and from yellow to green at $125 \mathrm{~mm}$ (more information about measurers and the MUAC device is provided in the Appendix). ${ }^{11}$

For the statistical analyses, we first calculated the nutritional indicators of severe wasting (more information is available in the Appendix), weight-forheight $z$ scores less than -3 for all children, according to the NCHS and WHO curves. We then compared the diagnostic accuracy of the 2 curves by using $2 \times 2$ tables to determine the sensitivity, specificity, positive predictive value, and Youden index (more information about Youden index estimation is available in the Appendix) ${ }^{12}$ of various MUAC cutoff points $(110,115$, $125,135,140$, and $145 \mathrm{~mm}$ ). The proportion of children with severe wasting who would be missed with the MUAC measure also was calculated. We used receiver operating characteristic curves to estimate the area under the curve ${ }^{13}$ for different MUAC cutoff values, to compare the discriminatory capacity of the WHO and NCHS curves for severe wasting.

To analyze the age and gender independence of the sensitivity and specificity of MUAC measurements in the diagnosis of severe wasting with the new curve, 2 logistic regression models were used to build receiver operating characteristic curves (more information about the models is available in the Appendix). The areas under both curves (unadjusted and adjusted for gender and height, as a proxy of age) were compared by using the test described by Hanley and McNeil. ${ }^{14}$

Finally, the age independence of the sensitivity and specificity of MUAC measurements in the diagnosis of severe wasting with the WHO and NCHS curves was assessed. Height was used as a proxy for age according to the following categories: 60.0 to $73.9 \mathrm{~cm}, 6$ to 11 months; 74.0 to $84.9 \mathrm{~cm}, 12$ to 23 months; 85.0 to $93.9 \mathrm{~cm}, 24$ to 35 months; 94.0 to $101.9 \mathrm{~cm}, 36$ to 47 months; 102.0 to $110.0 \mathrm{~cm}, 48$ to 59 months. ${ }^{15}$

\section{RESULTS}

According to the old NCHS reference curve, the prevalence of severe wasting (defined as the proportion of children 6 to 59 months of age with weight-forheight $z$ scores below -3 , without edema) was $1.5 \%$ (548 children). According to the new WHO curve, however, the prevalence was $3.9 \%$ (1419 children). The prevalence of severe wasting diagnosed with the new WHO reference curve increased by $2.4 \%$ ( $95 \%$ confidence interval [CI]: $2.2 \%-2.6 \%)$.

Table 1 shows the accuracy of various MUAC cutoff points according to both the NCHS and WHO reference curves. The best cutoff point for the diagnosis of severe wasting according to the NCHS curve was $130 \mathrm{~mm}$ (Youden index: 0.63), and that according to the WHO curve was $135 \mathrm{~mm}$ (Youden index: $0.61)$. The predictive capacity of MUAC 
measurements with these cutoff points improved remarkably when the WHO curve was used instead of the NCHS curve (NCHS curve, positive predictive value: $7.0 \%$ [95\% Cl: $6.3 \%-$ 7.6\%]; WHO curve, positive predictive value: $13.0 \%$ [95\% Cl: $12.2 \%-13.6 \%]$ ). In addition, the proportion of falsenegative results with a 135-mm MUAC cutoff value was $15.5 \%$ with the WHO standards and increased to $20.4 \%$ when the NCHS standards were used. However, it should be noted that the highest Youden index value was obtained when cases were defined by using the NCHS reference and a MUAC cutoff value of $130 \mathrm{~mm}$, rather than the WHO curve. On the basis of area-underthe-curve values, MUAC measurements performed better against the NCHS reference at cutoff values up to $140 \mathrm{~mm}$; it was only at 140 and $145 \mathrm{~mm}$ that such measurements performed better against the WHO curve. This difference was statistically significant (Hanley-McNeil test, MUAC cutoff value of $140 \mathrm{~mm}$, NCHS versus WHO curve, $z=2.5 ; P=.01 ;$ MUAC cutoff value of $145 \mathrm{~mm}$, NCHS versus WHO curve, $z=$ 2.2; $P=.02$ ). Graphically, the best MUAC cutoff point with the NCHS curve was confirmed to be $130 \mathrm{~mm}$ (area under the curve: 0.82 [95\% Cl: $0.79-0.83$ ]), and the best cutoff point with the WHO curve was $135 \mathrm{~mm}$ (area under the curve: 0.80 [95\% Cl: 0.79-0.82]) (Fig 1).

The predicted values of both logistic regression models (unadjusted and adjusted for height and gender) were used to build 2 receiver operating characteristic curves to analyze the age and gender independence of the sensitivity and specificity of MUAC measurements for the diagnosis of severe wasting by using the WHO standards. The areas under the curve, compared with the Hanley-McNeil test, did not differ statistically $(z=0.48 ; P>$ $.05)$. The area under the curve for the unadjusted curve was $0.89(95 \% \mathrm{Cl}$ :

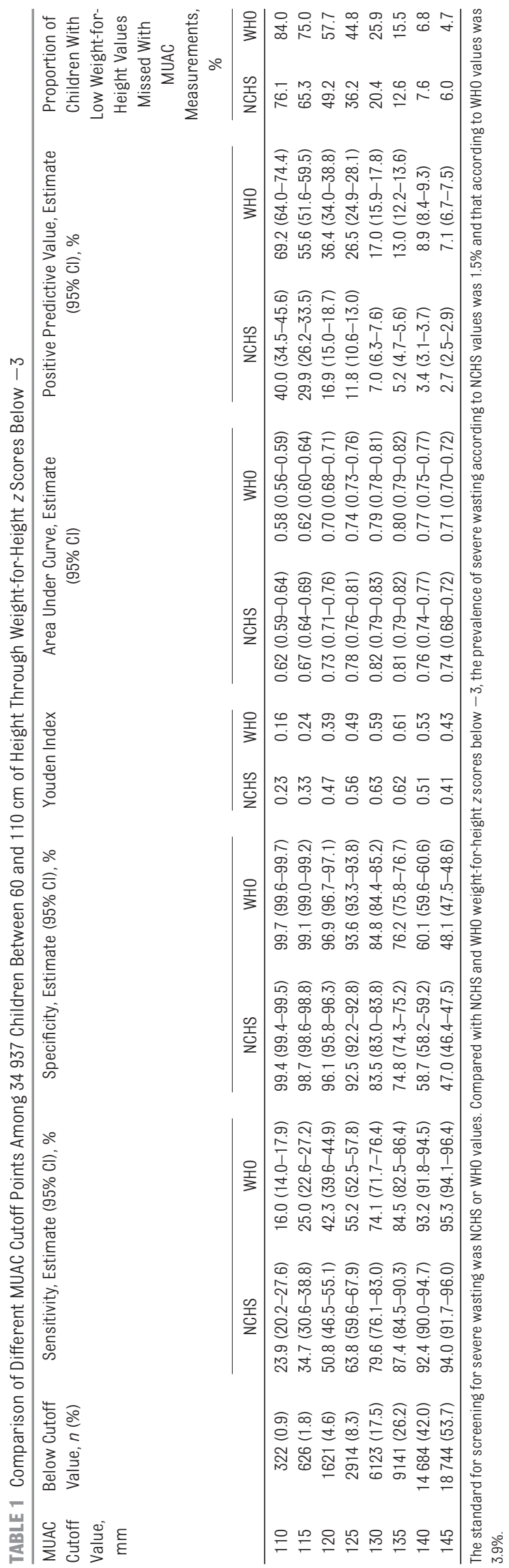



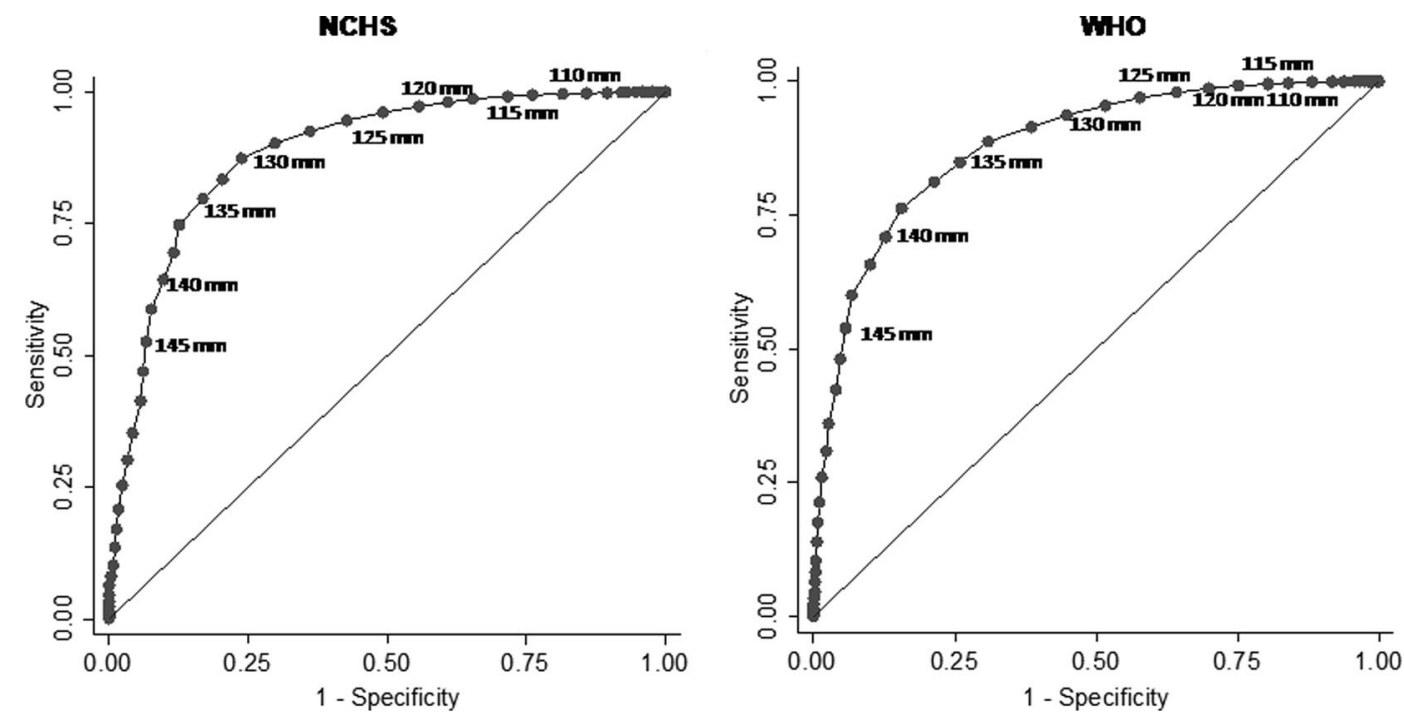

FIGURE 1

Receiver operating characteristic curves for severe wasting, defined as weight-for-height z scores below - 3, with NCHS (area under the curve: 0.82 [95\% Cl: $0.79-0.83]$ ) and WHO (area under the curve: 0.80 [95\% Cl: $0.79-0.82]$ ) standards and different MUAC cutoff values.

$0.88-0.90)$, and the area under the curve for the curve adjusted for gender and height was 0.90 ( $95 \% \mathrm{Cl}: 0.89-$ 0.92).

The results in Table 2 confirm this relative height (as a proxy for age) independence of the sensitivity and specificity of MUAC measurements for children between the ages of 6 and 59 months. For children 24 to 59 months of age, the sensitivity and specificity of MUAC measurements were independent of age; for children $<24$ months of age, however, the sensitivity and specificity of MUAC measurements were relatively independent of age.

\section{DISCUSSION}

Our results showed an increase in the number of children classified as having severe wasting when the new WHO curve was compared with older standards. This finding confirms the results of other studies. 16,17 This increased prevalence of severe wasting should have an impact on the planning of nutritional support programs in sub-Saharan Africa, because of the more-inclusive nature of the WHO standard-based case definition. During a famine, unstable conditions may make it difficult to determine the height and weight of children, and the use of MUAC measurements for children 6 to 59 months of age might overestimate severe wasting. With a higher cutoff point, false-positive results increase and malnutrition is therefore overestimated; however, false-negative results decrease.

MUAC was found to be the best indicator for screening and detection of malnutrition in a community. ${ }^{7}$ Screening methods based on comparisons with growth curves or weight gain are not likely to be predictive of mortality risk; arm circumference measurements, even without corrections for age or height, are substantially better than weight-for-age, height-for-age, or weight-for-height measurements. ${ }^{18} \mathrm{~A}$ MUAC cutoff point of $<110 \mathrm{~mm}$ was most related to mortality risk and therefore is suitable for use in malnutrition screening and detection efforts among children between 6 and 59 months of age. ${ }^{7,19-23}$ However, with the new WHO reference curve, an increase of $5 \mathrm{~mm}$ (from $110 \mathrm{~mm}$ to $115 \mathrm{~mm}$ ) in the MUAC cutoff value is necessary to maintain a level of diagnostic accuracy equal to that of the old curve.
With the new WHO curve, the overall performance of MUAC measurements, in terms of sensitivity and specificity, has deteriorated; therefore, to maintain the same diagnostic accuracy as the old curve and to identify the children at greatest risk of death resulting from severe wasting, a change in the cutoff value is needed. Our major findings are related to the need to change the MUAC cutoff point used to diagnose severe wasting from $<110 \mathrm{~mm}$ to $<115$ $\mathrm{mm}$. This increase of $5 \mathrm{~mm}$ produces a large change in sensitivity (from $16 \%$ to $25 \%$ ), with little loss in specificity. In addition, this increase improves the probability of diagnosing severe wasting, compared with the NCHS curve, and reduces false-negative results by $12 \%$ because of the more-inclusive nature of the WHO curve-based case definition.

The relative age and gender independence of the sensitivity and specificity of MUAC measurements and the ease of use are some of their most important characteristics. ${ }^{4-7}$ The results of our study also revealed that the age independence of the sensitivity and specificity of MUAC measurements improves with the switch from the NCHS standards 
TABLE 2 Sensitivity, Specificity, and Youden Index for MUAC Indicators in Identifying Severe Wasting (Weight-for-Height z Scores Below -3) Among 34937 Children 6 to 59 Months of Age, According to Height

\begin{tabular}{|c|c|c|c|c|c|c|c|}
\hline \multirow[t]{2}{*}{ Height (Age Proxy) } & \multirow{2}{*}{$\begin{array}{c}\text { MUAC } \\
\text { Cutoff } \\
\text { Value, } \mathrm{mm}\end{array}$} & \multicolumn{3}{|c|}{ WHO } & \multicolumn{3}{|c|}{ NCHS } \\
\hline & & $\begin{array}{c}\text { Sensitivity, } \\
\%\end{array}$ & $\begin{array}{c}\text { Specificity, } \\
\%\end{array}$ & $\begin{array}{l}\text { Youden } \\
\text { Index }\end{array}$ & $\begin{array}{c}\text { Sensitivity, } \\
\%\end{array}$ & $\begin{array}{c}\text { Specificity, } \\
\%\end{array}$ & $\begin{array}{c}\text { Youden } \\
\text { Index }\end{array}$ \\
\hline \multirow[t]{8}{*}{$60.0-73.9 \mathrm{~cm}(6-11 \mathrm{mo})$} & 110 & 32.0 & 99.0 & 0.31 & 48.1 & 97.6 & 0.46 \\
\hline & 115 & 47.8 & 97.4 & 0.45 & 68.8 & 95.3 & 0.64 \\
\hline & 120 & 71.8 & 90.4 & 0.62 & 89.6 & 87.4 & 0.77 \\
\hline & 125 & 84.6 & 81.6 & 0.66 & 92.2 & 78.2 & 0.70 \\
\hline & 130 & 93.2 & 62.9 & 0.56 & 97.4 & 59.9 & 0.57 \\
\hline & 135 & 95.3 & 50.4 & 0.46 & 98.7 & 48.0 & 0.47 \\
\hline & 140 & 98.5 & 29.7 & 0.28 & 100 & 28.2 & 0.28 \\
\hline & 145 & 99.4 & 19.3 & 0.19 & 100 & 18.3 & 0.18 \\
\hline \multirow[t]{8}{*}{$74.0-84.9 \mathrm{~cm}(12-23 \mathrm{mo})$} & 110 & 18.9 & 99.6 & 0.19 & 28.1 & 99.4 & 0.28 \\
\hline & 115 & 32.2 & 98.8 & 0.31 & 44.8 & 98.5 & 0.43 \\
\hline & 120 & 54.4 & 95.8 & 0.50 & 65.1 & 95.1 & 0.60 \\
\hline & 125 & 67.2 & 91.2 & 0.58 & 79.2 & 90.4 & 0.70 \\
\hline & 130 & 82.5 & 78.8 & 0.61 & 89.6 & 77.8 & 0.67 \\
\hline & 135 & 87.8 & 67.2 & 0.55 & 92.2 & 66.3 & 0.59 \\
\hline & 140 & 92.8 & 47.7 & 0.41 & 94.3 & 47.0 & 0.41 \\
\hline & 145 & 95.8 & 34.8 & 0.31 & 96.4 & 34.3 & 0.31 \\
\hline \multirow[t]{8}{*}{$85.0-93.9 \mathrm{~cm}(24-35 \mathrm{mo})$} & 110 & 12.7 & 99.9 & 0.13 & 25.0 & 99.8 & 0.25 \\
\hline & 115 & 17.8 & 99.7 & 0.18 & 28.3 & 99.6 & 0.28 \\
\hline & 120 & 34.7 & 98.6 & 0.33 & 43.5 & 98.2 & 0.42 \\
\hline & 125 & 51.2 & 96.7 & 0.48 & 63.0 & 96.1 & 0.59 \\
\hline & 130 & 73.7 & 90.7 & 0.64 & 79.3 & 89.7 & 0.69 \\
\hline & 135 & 83.1 & 83.8 & 0.67 & 88.0 & 82.8 & 0.71 \\
\hline & 140 & 92.0 & 68.6 & 0.61 & 92.4 & 67.7 & 0.60 \\
\hline & 145 & 94.4 & 56.2 & 0.51 & 93.5 & 55.4 & 0.49 \\
\hline \multirow[t]{8}{*}{$94.0-101.9 \mathrm{~cm}(36-47 \mathrm{mo})$} & 110 & 5.8 & 99.9 & 0.06 & 10.0 & 99.9 & 0.10 \\
\hline & 115 & 9.0 & 99.7 & 0.09 & 13.3 & 99.6 & 0.13 \\
\hline & 120 & 24.7 & 98.8 & 0.24 & 27.8 & 98.4 & 0.26 \\
\hline & 125 & 38.1 & 97.2 & 0.35 & 40.0 & 96.5 & 0.37 \\
\hline & 130 & 61.9 & 92.3 & 0.54 & 65.6 & 91.3 & 0.57 \\
\hline & 135 & 76.7 & 86.0 & 0.63 & 78.9 & 84.7 & 0.64 \\
\hline & 140 & 89.7 & 72.8 & 0.63 & 88.9 & 71.6 & 0.61 \\
\hline & 145 & 91.0 & 61.3 & 0.52 & 90.0 & 60.2 & 0.50 \\
\hline \multirow[t]{8}{*}{$102.0-110.0 \mathrm{~cm}(48-59 \mathrm{mo})$} & 110 & 2.7 & 100 & 0.03 & 7.0 & 100.0 & 0.07 \\
\hline & 115 & 4.9 & 99.9 & 0.05 & 11.6 & 99.9 & 0.12 \\
\hline & 120 & 9.1 & 99.7 & 0.09 & 17.4 & 99.5 & 0.17 \\
\hline & 125 & 19.4 & 98.9 & 0.18 & 31.4 & 98.5 & 0.30 \\
\hline & 130 & 49.0 & 95.7 & 0.45 & 57.0 & 94.5 & 0.52 \\
\hline & 135 & 74.1 & 90.2 & 0.64 & 75.6 & 88.3 & 0.64 \\
\hline & 140 & 91.3 & 78.2 & 0.63 & 86.0 & 76.1 & 0.62 \\
\hline & 145 & 93.9 & 66.3 & 0.60 & 88.4 & 64.5 & 0.53 \\
\hline
\end{tabular}

to the new WHO curve. When the NCHS reference curve is used, the sensitivity and specificity of MUAC measurements are at their most age dependent and the MUAC cutoff value increases by $1.5 \mathrm{~cm}$ between the ages of 6 and 59 months. With the new curve, an increase of only 1 $\mathrm{cm}$ is targeted among children between the ages of 6 and 59 months.

Other researchers also found that the MUAC cutoff points increase by $1.5 \mathrm{~cm}$ between the ages of 6 and 59 months according to the NCHS curve. ${ }^{24-26}$ This reinforces the validity of our finding that the relative age independence of the sensitivity and specificity of MUAC measurements improves with the new curve. The improved predictive capacity and the relative age independence of the sensitivity and specificity of MUAC measurements indicate that the standards of the new WHO curve are better able to screen for severe wasting. ${ }^{27}$

Our study may contain a classification bias, because the surveys were conducted in 10 different countries at dif- ferent times and by different staff members. Similarly, we think that there might have been a selection bias related to the ethnicity of the children. Anthropometric nutritional surveys from Ethiopia and Somalia found that $z$ scores and MUAC case definitions returned different estimates of the prevalence of acute malnutrition in pastoralist livelihood zones but similar estimates of the prevalence of severe wasting in agrarian livelihood zones. ${ }^{28}$ Nevertheless, the new WHO curve uses 
a pooled sample from the 6 participating countries and provides a tool that is timely and appropriate for contemporary ethnic diversity and the development of increasingly multiracial societies. The WHO curve also demonstrates that healthy children from around the world who are raised in healthy environments, according to recommended feeding practices, have strikingly similar patterns of growth.$^{29}$

\section{CONCLUSIONS}

With the new WHO curve, the performance of MUAC measurements has deteriorated. This poorer performance, in terms of sensitivity and specificity, confirms the need to change the MUAC cutoff value from $<110 \mathrm{~mm}$ to $<115$ $\mathrm{mm}$. This increase of $5 \mathrm{~mm}$ produces a large change in sensitivity (16\% to $25 \%)$ with little loss in specificity, improves the probability of diagnosing severe wasting, and reduces falsenegative results by $12 \%$. This change is needed to maintain the same diagnostic accuracy as the old curve and to identify the children at greatest risk of death resulting from severe wasting.

\section{APPENDIX}

\section{MUAC Measurers}

The measurers were people already working in nutritional programs. The measurers were supervised by a person who was responsible for proper

\section{REFERENCES}

1. Bray GA, Greenway FL, Molitch ME, Dahms WT, Atkinson RL, Hamilton K. Use of anthropometric measures to assess weight loss. Am J Clin Nutr. 1978;31(5):769-773

2. Harries AD, Jones LA, Heatley RV, Newcombe $\mathrm{RG}$, Rhodes J. Precision of anthropometric measurements: the value of mid-arm circumference. Clin Nutr. 1984;2(3-4):193-196

3. Ross DA, Taylor N, Hayes R, McLean M. Measuring malnutrition in famines: are weightfor-height and arm circumference interchangeable? Int J Epidemiol. 1990;19(3): 636-645

4. Waterlow JC. Note on the assessment and application of the sampling procedures and was responsible for a team with respect to the measurements and other procedures defined in the survey guidelines. All measurers were trained by a nutritional nurse regarding the proper gathering of anthropometric measurements. A pretest was conducted to test the teams and the reliability of primary measurements. At the end of the pretest, the quality of the anthropometric measurements taken by the measurers was reviewed.

\section{Device Used to Measure MUAC}

The device used was a plastic, colored, insertion tape (incapable of stretching and unresponsive to temperatures) marked in millimeters, with cutoff points from red to yellow at $110 \mathrm{~mm}$ and from yellow to green at $125 \mathrm{~mm}$.

\section{Calculation of Indicator of Severe Wasting (Weight-for-Height z Score)}

Severe wasting, defined as weight-forheight $z$ scores below -3 for all children according to the NCHS curve, were calculated with Epi Info 6 (Centers for Disease Control and Prevention, Atlanta, GA). The $z$ scores for the new WHO standards were calculated with the igrowup macro package (available at www.who.int/childgrowth/ software/en).

classification of protein-energy malnutrition in children. Lancet. 1973;2 (7820):87-89

5. Vijayaraghavan K, Sastry JG. The efficacy of arm circumference as a substitute for weight in assessment of protein-calorie malnutrition. Ann Hum Biol. 1976;3(3): 229-233

6. Velzeboer MI, Selwyn BJ, Sargent F II, Pollitt $E$, Delgado H. Evaluation of arm circumference as a public health index of protein energy malnutrition in early childhood. $J$ Trop Pediatr. 1983;29(3):135-144

7. Myatt M, Khara T, Collins S. A review of methods to detect cases of severely mal-
Estimation of Age and Gender Independence of Sensitivity and Specificity of MUAC Cutoff Values From WHO Curve

Two logistic regression models were used to analyze the age and gender independence of the sensitivity and specificity of MUAC measurements in the diagnosis of severe wasting according to the WHO curve. The first model was built by using the WHO dichotomous indicator (yes/no) of severe wasting as a dependent variable and MUAC as an independent variable. The second model was adjusted for gender and height (as a proxy for age). The models were as follows: unadjusted model: log (severe wasting) $=$ $\beta_{0}+\left(\beta_{1} \times\right.$ MUAC); adjusted model: $\log$ (severe wasting $)=\beta_{0}+\left(\beta_{1} \times\right.$ MUAC $)+\left(\beta_{2} \times\right.$ height $)+\left(\beta_{3} \times\right.$ gender). The predicted values of both models were used to build 2 receiver operating characteristic curves. The areas under the curves were compared with the Hanley-McNeil test.

\section{Youden Index}

The Youden index represents an attempt to summarize test accuracy into a single numeric value, that is, Youden index $=$ sensitivity + specificity $-1=$ $S-(1-E)$. The minimum value is -1 and the maximum value is +1 . A perfect test would have a Youden index value of +1 .

nourished children in the community for their admission into community-based therapeutic care programs. Food Nutr Bull. 2006;27 (3 suppl):S7-23

8. de Onis M, Onyango AW, Borghi E, Garza C, Yang $\mathrm{H}$; World Health Organization, Multicentre Growth Reference Study Group. Comparison of the World Health Organization (WHO) Child Growth Standards and the National Center for Health Statistics/WHO international growth reference: implications for child health programmes. Public Health Nutr. 2006;9(7):942-947

9. Waterlow JC, Buzina R, Keller W, Lane JM, 
Nichaman MZ, Tanner JM. The presentation and use of height and weight data for comparing the nutritional status of groups of children under the age of 10 years. Bull World Health Organ. 1977;55(4):489-498

10. World Health Organization, Multicentre Growth Reference Study Group. WHO Child Growth Standards: Length/height-for-age, weight-for-age, weight-for-length, weightfor-height and body mass index-for-age: Methods and development. Geneva: World Health Organization; 2006

11. Zerfas AJ. The insertion tape: a new circumference tape for use in nutritional assessment. Am J Clin Nutr. 1975;28(7):782-787

12. Youden WJ. Index for rating diagnostic tests. Cancer. 1950;3(1):32-35

13. Faraggi D, Reiser B. Estimation of the area under the ROC curve. Stat Med. 2002;21 (20): 3093-3106

14. Hanley JA, McNeil BJ. A method of comparing the areas under receiver operating characteristic curves derived from the same cases. Radiology. 1983;148(3): 839-843

15. Bern C, Nathanail L. Is mid-upper-arm circumference a useful tool for screening in emergency settings? Lancet. 1995; 345(8950):631-633

16. Lapidus N, Luquero FJ, Gaboulaud V, Shepherd S, Grais RF. Prognostic accuracy of
WHO growth standards to predict mortality in a large-scale nutritional program in $\mathrm{Ni}$ ger. PLoS Med. 2009;6(3):e39

17. Lapidus N, Minetti A, Djibo A, et al. Mortality risk among children admitted in a largescale nutritional program in Niger, 2006. PLoS One. 2009;4(1):e4313

18. Briend A, Garenne M, Maire B, Fontaine 0, Dieng K. Nutritional status, age and survival: the muscle mass hypothesis. Eur J Clin Nutr. 1989;43(10):715-726

19. Vella V, Tomkins A, Ndiku J, Marshal T, Cortinovis I. Anthropometry as a predictor for mortality among Ugandan children, allowing for socio-economic variables. Eur J Clin Nutr. 1994;48(3):189-197

20. Berkley J, Mwangi I, Griffiths K, et al. Assessment of severe malnutrition among hospitalized children in rural Kenya: comparison of weight for height and mid upper arm circumference. JAMA. 2005;294(5):591-597

21. Briend A, Wojtyniak B, Rowland MG. Arm circumference and other factors in children at high risk of death in rural Bangladesh. Lancet. 1987;2 (8561):725-728

22. Chen LC, Chowdhury A, Huffman SL. Anthropometric assessment of energy protein malnutrition and subsequent risk of mortality among preschool-aged children. Am J Clin Nutr. 1980;33(8):1836-1845

23. Trowbridge FL, Sommer A. Nutritional an- thropometry and mortality risk. Am J Clin Nutr. 1981;34(11):2591-2592

24. Anderson MA. Comparison of anthropometric measures of nutritional status in preschool children in five developing countries. Am J Clin Nutr. 1979;32(11):2339-2345

25. Gayle HD, Binkin NJ, Staehling NW, Trowbridge FL. Arm circumference v. weight-forheight in nutritional assessment: are the findings comparable? J Trop Pediatr. 1988; 34(5):213-217

26. de Onis M, Yip R, Mei Z. The development of MUAC-for-age reference data recommended by a WHO expert committee. Bull World Health Organ. 1997;75(1):11-18

27. Garza C, de Onis M; World Health Organization, Multicentre Growth Reference Study Group. Rationale for developing a new international growth reference. Food Nutr Bull. 2004;25 (suppl 1):S5-S14

28. Myatt M, Duffield A, Seal A, Pasteur F. The effect of body shape on weight-for-height and mid-upper arm circumference based case definitions of acute malnutrition in Ethiopian children. Ann Hum Biol. 2009; 36(1):5-20

29. de Onis M, Garza C, Onyango AW, RollandCachera MF; le Comité de Nutrition de la Société Française de Pédiatrie. WHO growth standards for infants and young children [in French]. Arch Pediatr. 2009;16(1):47-53 


\section{Accuracy of MUAC in the Detection of Severe Wasting With the New WHO Growth Standards}

Miguel Ángel Luque Fernández, Pascale Delchevalerie and Michel van Herp Pediatrics 2010;126; e195; originally published online June 29, 2010; DOI: $10.1542 /$ peds. $2009-2175$

\section{Updated Information \& Services}

\section{References}

Subspecialty Collections

Permissions \& Licensing

Reprints including high resolution figures, can be found at: http://pediatrics.aappublications.org/content/126/1/e195.full.h tml

This article cites 28 articles, 9 of which can be accessed free at:

http://pediatrics.aappublications.org/content/126/1/e195.full.h tml\#ref-list-1

This article, along with others on similar topics, appears in the following collection(s):

Infectious Diseases

http://pediatrics.aappublications.org/cgi/collection/infectious_ diseases_sub

Epidemiology

http://pediatrics.aappublications.org/cgi/collection/epidemiolo gy_sub

Information about reproducing this article in parts (figures, tables) or in its entirety can be found online at:

http://pediatrics.aappublications.org/site/misc/Permissions.xht $\mathrm{ml}$

Information about ordering reprints can be found online: http://pediatrics.aappublications.org/site/misc/reprints.xhtml

PEDIATRICS is the official journal of the American Academy of Pediatrics. A monthly publication, it has been published continuously since 1948. PEDIATRICS is owned, published, and trademarked by the American Academy of Pediatrics, 141 Northwest Point Boulevard, Elk Grove Village, Illinois, 60007. Copyright ( 2010 by the American Academy of Pediatrics. All rights reserved. Print ISSN: 0031-4005. Online ISSN: 1098-4275.

\section{American Academy of Pediatrics}

